\title{
Antioxidant properties of PF9601N, a novel MAO-B inhibitor: assessment of its ability to interact with reactive nitrogen species
}

\author{
Lydia Bellik1, Stefania Dragoni', Federica Pessina1', Elisenda Sanz², Mercedes Unzeta² and \\ Massimo Valoti ${ }^{\bowtie}$
}

1Dipartimento di Neuroscienze, Università di Siena, Italy, ²Departamento de Bioquimica i Biologia Molecular, Universitat Autonoma de Barcelona, Spain

The novel MAO-B inhibitor PF9601N, its cytochrome P450-dependent metabolite FA72 and I-deprenyl were studied as potential peroxynitrite (ONOO-) scavengers and nitric oxide synthase (NOS) inhibitors. The scavenging activity of these compounds was evaluated by measuring the oxygen consumption through peroxynitrite-mediated oxidation of both linoleic acid and brain homogenate. FA72, PF9601N and L-deprenyl caused a concentration-dependent inhibition of ONOO--induced linoleic acid oxidation with an IC $\mathrm{C}_{50}$ value of $60.2 \mu \mathrm{M}, 82.8$ $\mu \mathrm{M}$ and $235.8 \mu \mathrm{M}$, respectively. FA72 was the most potent also in inhibiting ONOO--induced brain homogenate oxidation with an $\mathrm{IC}_{50}$ value of $99.4 \mu \mathrm{M}$, while PF9601N and L-deprenyl resulted weaker inhibitors in the same experimental model, showing an $\mathrm{IC}_{50}$ value of 164.8 and $112.0 \mu \mathrm{M}$, respectively. Furthermore, both the novel MAO-B inhibitor as well as its metabolite were able to strongly inhibit rat brain neuronal NOS $\left(I_{50}\right.$ of $183 \mu \mathrm{M}$ and $192 \mu \mathrm{M}$, respectively), while L-deprenyl at the highest concentration used ( $3 \mathrm{mM})$, caused only a slight decrease of the enzyme activity. Moreover, inducible NOS was strongly inhibited by FA72 only. All these results suggest that PF9601N could be a promising therapeutic agent in neurodegenerative disorders such as Parkinson's disease.

Keywords: MAO-B inhibitors, L-deprenyl, Parkinson's disease, peroxynitrite, nitric oxide

Received: 02 April, 2010; revised: 04 May, 2010; accepted: 04 June, 2010; available on-line: 09 June, 2010

\section{INTRODUCTION}

Oxidative stress is thought to be an important contributor to neuronal damage in neurodegenerative disorders. Different cellular components such as lipids, proteins, DNA undergo oxidative reactions; moreover, the resulting degenerative products may react with other biological macromolecules to impair cell viability and cause the loss of neurons in different brain areas. In particular, loss of the dopaminergic neurons of substantia nigra pars compacta may lead to the Parkinson's disease (PD). Different studies have demonstrated that oxidative stress contributes to the cascade leading to dopamine cell degeneration and is intimately linked to other components of the degenerative process, such as mitochondrial dysfunction, excito- toxicity, inflammation and nitric oxide toxicity (Schapira et al., 1990; Bolaños et al., 1997; Rodriguez et al., 1998).

$\mathrm{NO}$ is a free radical species produced by different mammalian cell types and is involved in several physiological and pathological conditions. There is, indeed, considerable evidence showing that oxidative stress and oxidative damage occurring in PD might result from several actions of NO. The toxicity of NO would be mediated by reactive nitrogen species and also by the reaction of $\mathrm{NO}$ with superoxide to form $\mathrm{ONOO}^{-}$, which not only is an oxidizing agent on its own but degrades to form hydroxyl radicals, among other radical species (Beckman et al., 1990). The substantia nigra in PD showed increased immunoreactivity for inducible nitric oxide synthase (iNOS), presumably as a result of glial cell activation (Hunot et al., 1996). Increased protein damage resulting from attack by $\mathrm{ONOO}^{-}$is found in the core of Lewy bodies as measured by 3-nitrotyrosine immunoreactivity (Duda et al., 2000). Indirect evidence similarly implicates $\mathrm{NO}$ in the mechanisms underlying nigral cell degeneration as NOS inhibitors protect against MPTP/ $\mathrm{MPP}^{+}$-induced experimental PD in mice and monkeys (Schulz et al., 1995; Hantraye et al., 1996). This presumably relates to the effect of $\mathrm{MPP}^{+}$on mitochondrial function to initiate excitotoxic mechanisms and activate NO formation. Mice deficient for either neuronal NOS (nNOS) or iNOS (Przedborski et al., 1996; Liberatore et al., 1999) show reduced toxicity to MPTP. The toxic effects of $\mathrm{NO} \mathrm{ONOO}^{-}$can also involve damage to DNA leading to products such as 8-hydroxyguanine and 8-nitrodeoxyguanosine and increase in DNA single-strand breakage (Byun et al., 1999).

In this context, the development of new molecules able to reduce the oxidative stress, thereby slowing the rate of neuronal degeneration, appears to be necessary. A new series of acetylenic and allenic derivatives of tryptamine synthesised as MAO-B inhibitors (MAOIs) have been described (Avila et al., 1993; Perez et al., 1999). Among these, the 5-benzyloxy derivatives have shown themselves to be highly potent and selective MAO-B inhibitors (Perez et al., 1999), and N-(2-propynyl)-2-(5benzyloxy-indolyl) methylamine (PF9601N) was shown

\footnotetext{
e-mail: valoti@unisi.it
}

Abbreviations: DTPA diethylenetriaminepentaacetic acid; $E R$, endoplasmic reticulum; MAO-B, monoamine oxidase $B$; MAOIs, MAO$\mathrm{B}$ inhibitors; MPP, 1-methyl-4-phenylpyrinidinum; MPTP, 1-methyl4-phenyl-1,2,3,6-tertrahydropyridine; NOS, nitric oxide synthase; 6-OH DA, 6-hydroxydopamine; PD, Parkinson's disease. 
to have a neuroprotective effect in several experimental models of PD. PF9601N protects nigrostriatal dopamine neurons against MPTP neurotoxicity in C57BL/6 adult mice (Perez et al., 2003) and protects rat nigral neurons after 6-hydroxydopamine striatal lesion (Cutillas et al., 2002). It has also been demonstrated that PF9601N enhances the duration of L-DOPA-induced contralateral turning of 6-OH DA-lesioned rats (Prat et al., 2000) and prevents cell death induced by complex I inhibition and ER stress, two of the suggested underlying mechanisms of neurodegeneration in PD (Sanz et al., 2008; 2009). Finally, antioxidant properties of PF9601N have been demonstrated in vitro and by its neuroprotective effect observed in SHSY5Y dopaminergic cells damaged with dopamine (Sanz et al., 2004).

On the base of the above observations, the aim of this study was to investigate the protective effects of PF9601N and its cytochrome P450-dependent metabolite FA-72 (Dragoni et al., 2007) on NO system, both by measuring their effects on $\mathrm{ONOO}^{-}$-mediated oxidation and the influence on NOS activity. The same experiments were performed with the MAO-B inhibitor L-deprenyl, used with L-DOPA in the therapy of PD (Knoll, 1986).

\section{MATERIALS AND METHODS}

Chemicals. Linoleic acid and human recombinant nitric oxide synthase were obtained from Sigma (St. Louis, MO, USA). N-(2-propynyl)-2-(5-benzyloxy-indolyl) methylamine or PF9601N, and 5-benzyloxy-indol)methylamine or FA72 were synthesized in our laboratory. L-(-)-N, $\alpha$-dimethyl-N-2-propynylphenethyl-amine hydrochloride (L-deprenyl-HCl) was a gift from Chinoin Chemical Works (Budapest, Hungary). All other chemicals and solvents were of the highest grade available and were obtained from common commercial sources.

Peroxynitrite synthesis. Peroxynitrite was synthesized in a quenched flow reactor and stored in $1.5 \mathrm{M}$ $\mathrm{NaOH}$ at $-70^{\circ} \mathrm{C}$, as previously described by Beckmann et al. (1994). Its concentration was determined spectrophotometrically by measuring absorbance at $302 \mathrm{~nm}$ $\left(\varepsilon=1670 \mathrm{M}^{-1} \cdot \mathrm{cm}^{-1}\right)$ as described by Kooy et al. (1997).

Effect of MAO inhibitors on peroxynitrite-mediated oxidation of linoleic acid and brain homogenate. Peroxynitrite scavenging activity was assayed by following $\mathrm{ONOO}^{-}$-promoted oxidation of linoleic acid through oxygen consumption measured with a Clark oxygen electrode (Patel \& Darley-Usmar, 1996). The electrode chamber was filled with $33 \mathrm{mM}$ linoleic acid in $50 \mathrm{mM}$ phosphate buffer, $\mathrm{pH}$ 7.4, containing $100 \mu \mathrm{M}$ DTPA, with variable concentrations $(10-1000 \mu \mathrm{M})$ of MAO-B inhibitors (MAOIs) or FA72 in $3 \mathrm{ml}$ final volume, and oxygen consumption was measured at $37^{\circ} \mathrm{C}$ for $3 \mathrm{~min}$. The reaction was started by adding $500 \mu \mathrm{M}$ peroxynitrite to the assay mixture and oxygen consumption was monitored for $10 \mathrm{~min}$.

In a second series of experiments linoleic acid was replaced by brain homogenate at a final protein concentration of $1 \mathrm{mg} / \mathrm{ml}$. All experiments were performed in triplicate and controls were obtained by measuring linoleic acid or brain homogenate oxidation in the presence of $\mathrm{ONOO}^{-}$alone. All solutions were made using high purity deionized water.

Spectrum changes of MAO inhibitors in the presence of peroxynitrite. The reaction of the tested compounds and $\mathrm{ONOO}^{-}$was followed spectrophoto- metrically at 500-220 nm with a double beam UV-visible spectrophotometer (Shimadzu UV-1601). The reaction

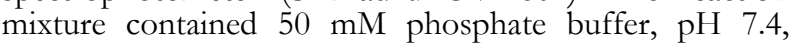
$100 \mu \mathrm{M}$ MAOIs and $100 \mu \mathrm{M} \mathrm{ONOO}^{-}$added under vigorous stirring. The spectra were recorded every $60 \mathrm{~s}$. A blank cuvette contained reaction mixture without $\mathrm{ONOO}^{-}$.

nNOS preparations. Rats were fasted overnight prior to the sacrifice by $\mathrm{CO}_{2}$ asphyxia. Brains were quickly removed and freed from cerebral vessels. Each sample was processed individually. The tissues were chopped and suspended in five volumes of $20 \mathrm{mM}$ Hepes buffer, $\mathrm{pH}$ 7.2 containing $320 \mathrm{mM}$ sucrose, $1 \mathrm{mM}$ EDTA, $1 \mathrm{mM}$ DT'T, $10 \mu \mathrm{g} / \mathrm{ml}$ leupeptine, $10 \mu \mathrm{g} / \mathrm{ml}$ trypsine soybean inhibitor, $2 \mu \mathrm{g} / \mathrm{ml}$ aprotinine and $0.1 \mathrm{mM}$ phenylmethylsulfonyl fluoride, and homogenized as reported by Knowles and Salter (1998). The homogenate was centrifuged at $120000 \times \mathrm{g}$ for $30 \mathrm{~min}$ at $4^{\circ} \mathrm{C}$ (Chen et al., 1997) and supernatant was batch-treated with Dowex $50 \mathrm{w}$ to remove the endogenous arginine.

Nitric oxide production was measured using a spectrophotometric method by following the oxidation of oxyhemoglobin to methemoglobin at $37^{\circ} \mathrm{C}$ in a reaction

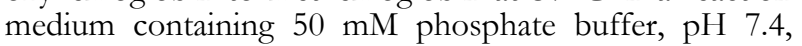
$250 \mu \mathrm{M} \mathrm{CaCl}, 100 \mu \mathrm{M}$ NADPH, $10 \mu \mathrm{M}$ dithiothreitol, $1.0 \mathrm{mg}$ submitochondrial protein $/ \mathrm{ml}$ and $25 \mu \mathrm{M}$ oxyhemoglobin (expressed per heme group). The reaction was started by adding $20 \mu \mathrm{M}$ L-arginine. Kinetics were followed at $\lambda 401-421 \mathrm{~nm}\left(\varepsilon=77200 \mathrm{M}^{-1} \cdot \mathrm{cm}^{-1}\right)$. The same assay was used to study the effects of the tested compounds on iNOS.

\section{RESULTS}

\section{Scavenger properties of MAOls}

To study the protective effect of MAOIs on peroxynitrite $\left(\mathrm{ONOO}^{-}\right)$-induced lipid peroxidation brain homogenates or linoleic acid were treated with $\mathrm{ONOO}^{-}$in combination with different concentrations of PF9601N, FA72 and L-deprenyl. The reaction of peroxynitrite with linoleic acid is rather complex and leads to the formation of oxidised and nitrated products (O'Donnel et al., 1999) that contribute to oxygen consumption. In a similar manner 'NO-derived reactive species (e.g., peroxynitrite anion, nitrogen dioxide radical) react with lipids containing unsaturated fatty acids to generate nitrated species and oxygenated species (Lima et al., 2003).

Preliminary experiments showed that the oxygen consumption in the presence of either linoleic acid or brain homogenate was linear in respect to the concentration of $\mathrm{ONOO}^{-}$in the range of $50-500 \mu \mathrm{M} ; 500 \mu \mathrm{M}$ was the concentration that gave the highest oxidation rate.

As shown in Fig. 1, when the studied compounds were present in the incubation medium, a concentration-dependent inhibition of oxygen consumption was observed for both linoleic acid and brain homogenate. PF9601N and its cytochrome P450 (CYP)-dependent metabolite FA72 showed the highest inhibitory effects on the $\mathrm{ONOO}^{-}$-induced linoleic acid oxidation (Fig. 1) with the $\mathrm{IC}_{50}$ values of $82.8 \pm 2.0 \mu \mathrm{M}$ and $60 \pm 1.2 \mu \mathrm{M}$, respectively, values about 3 -fold lower than that observed for L-deprenyl $(235.8 \pm 6.0 \mu \mathrm{M})$. When the experiments were performed using brain homogenate the observed antioxidant activity of Ldeprenyl was poorer, with the $\mathrm{IC}_{50}$ value one order of magnitude higher than those for PF9601N and FA72 (see Table 1). 


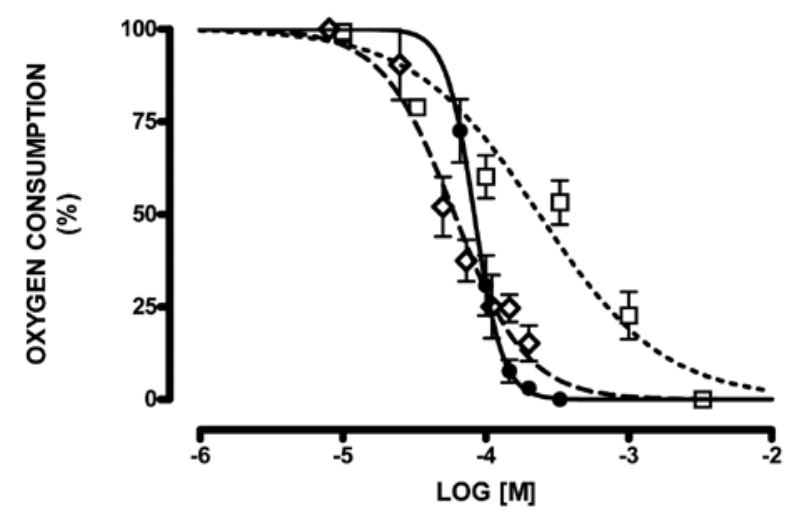

Figure 1. Effects of MAOIs on linoleic acid oxidation promoted by ONOO-.

Inhibition of oxygen consumption in presence of $33 \mathrm{mM}$ linoleic acid at different concentrations $\left(10^{-5} \mathrm{M}-3.0 \times 10^{-3} \mathrm{M}\right)$ of $(\square) \mathrm{L}$ deprenyl, (O) PF9601N, or $(\diamond)$ FA72 in buffer at pH 7.4. Reaction was started by adding $500 \mu \mathrm{M} \mathrm{ONOO}^{-}$to assay mixture. Data are reported as percentage of control value. Data are means \pm SEM of three independent experiments.

In order to clarify if the compounds were chain-reaction breakers, the compounds were added to the reaction mixture containing linoleic acid $3 \mathrm{~min}$ after $\mathrm{ONOO}^{-}$addition. In these experiments, all the compounds showed weaker antioxidant properties, and at the highest concentrations used PF9601N and FA72 (1 mM) and L-deprenyl $(3 \mathrm{mM})$ only showed a non-significant inhibitory effect (not shown).

\section{UV-Visible spectrophotometric analysis}

The reaction of MAOI compounds and FA72 with $100 \mu \mathrm{M} \mathrm{ONOO}^{-}$was monitored by UV-visible analysis. When $100 \mu \mathrm{M}$ PF9601N, FA72 or L-deprenyl were incubated in phosphate buffer, $\mathrm{pH} 7.4$, (control conditions), no spectral changes were recorded during the 30 min period of observation. However, when the spectra were recorded after the addition of $100 \mu \mathrm{M} \mathrm{ONOO}^{-}$, a time-dependent change of the spectra was observed for all compounds studied. In particular, an increase in the

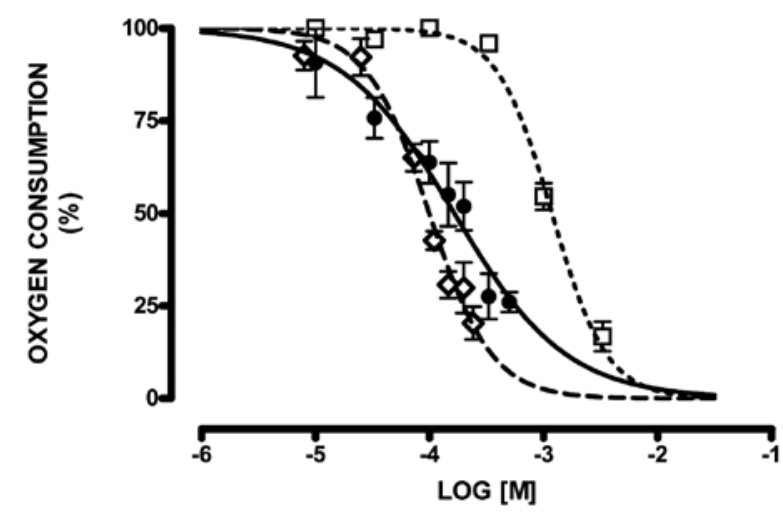

Figure 2. Effects of MAOls on brain homogenate oxidation promoted by ONOO-.

Inhibition of oxygen consumption in presence of $1 \mathrm{mg} / \mathrm{ml}$ brain homogenate at different concentrations $\left(10^{-5} \mathrm{M}-3.0 \times 10^{-3} \mathrm{M}\right)$ of $(\square)$ L-deprenyl, $(\bullet)$ PF9601N, or $(\diamond)$ FA72 in buffer at pH 7.4. Reaction was started by adding $500 \mu \mathrm{M}$ ONOO- to assay mixture. Data are reported as percentage of control value. Data are means \pm SEM of $\%$ of three independent experiments. absorbance between $350 \mathrm{~nm}$ and $280 \mathrm{~nm}$ and a decrease in the absorbance at $\lambda 250-230 \mathrm{~nm}$ was observed.

\section{Effect of MAOIs on NOS activity}

The in vitro inhibitory properties of the three MAOIs were examined on constitutive rat brain NOS. Enzyme preparations showed a $K_{\mathrm{m}}$ towards arginine and a $V_{\max }$ $\left(K_{\mathrm{m}}=1562 \pm 0.2 \mu \mathrm{M} V_{\max } 0.34 \pm 0.01 \mathrm{nmol} / \mathrm{min}\right.$ per $\mathrm{mg}$ protein) similar to those reported by other authors. In our experimental conditions the NO formation rate was linear up to $15 \mathrm{~min}$ of the reaction. In those conditions both PF9601N and its metabolite FA-72 caused a concentration-dependent inhibition of nNOS with similar $\mathrm{IC}_{50}$ values of $183 \mu \mathrm{M}$ and $192 \mu \mathrm{M}$, respectively. LDeprenyl was less active, producing only approx. 20\% inhibition at the highest concentration tested of $1 \mathrm{mM}$ (Fig. 3).

L-Deprenyl presented a similar behaviour also when incubated in the presence of iNOS. It should be observed, however, that only FA72 was able to inhibit iNOS with an $\mathrm{IC}_{50}$ similar to that for nNOS, while its parent compound caused only a weak inhibition (see Table 1).

\section{DISCUSSION}

In this study it was demonstrated that all the compounds tested were able to inhibit peroxynitrite-mediated oxidation of both linoleic acid and brain homogenate, although with a different potency. Furthermore, this property seems to be related to a direct reaction with peroxynitrite more than to the free radical scavenging property. In fact when the compounds were added to the assay mixture $3 \mathrm{~min}$ after $\mathrm{NOO}^{-}$addition, a time during which the linoleic acid oxidation rate increased and all NO disappeared, only a weak inhibition of oxygen consumption was detected. Moreover, the direct interaction of MAO inhibitors with $\mathrm{NOO}^{-}$was confirmed by the changes of the UV-visible spectral properties occurring when

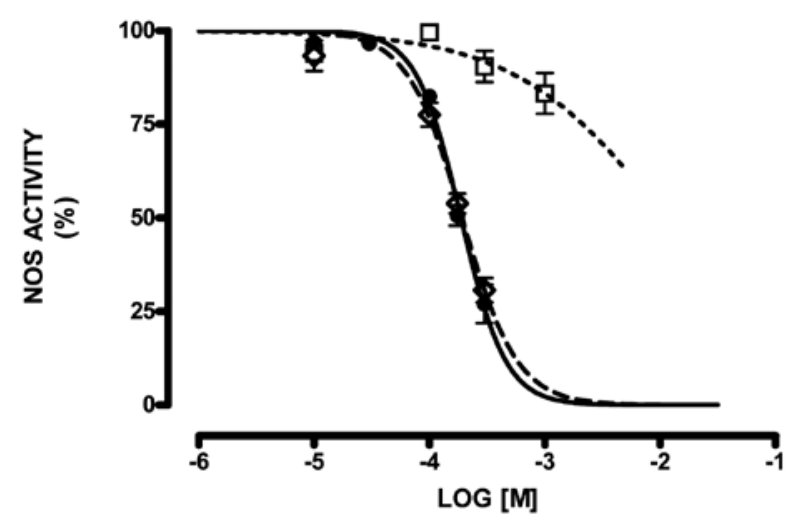

Figure 3. Concentration-dependent inhibition of brain nitric oxide synthase by compounds tested.

Partially purified rat brain nNOS $(1 \mathrm{mg} / \mathrm{ml}$ proteins) was incubated in presence of different concentrations $\left(10^{-5} \mathrm{M}-10^{-3} \mathrm{M}\right)$ of $(\square)$ L-deprenyl, (৩) PF9601N or $(\diamond)$ FA72 in phosphate buffer, pH 7.4, containing $250 \mu \mathrm{M} \mathrm{CaCl}_{2}, 10 \mu \mathrm{M}$ DTT and $100 \mu \mathrm{M}$ NADPH. The reaction was started by adding $20 \mu \mathrm{M}$ arginine to assay solution. NO production was followed spectrophotometrically by measuring oxidation of haemoglobin to methemoglobin at $\lambda 401-421 \mathrm{~nm}$. Data are reported as percentage of control value and are means \pm SEM of at least four independent experiments. 
Table 1. Effects of tested compounds on NO system

\begin{tabular}{|c|c|c|c|c|}
\hline \multirow[t]{2}{*}{ Compounds } & \multicolumn{2}{|l|}{ Peroxynitrite inhibition } & \multicolumn{2}{|l|}{ NOS inhibition } \\
\hline & $\begin{array}{l}\text { Linoleic acid oxidation } \\
\qquad \mathrm{IC}_{50}(\mu \mathrm{M})\end{array}$ & $\begin{array}{l}\text { Brain homogenate oxidation } \\
\qquad \mathrm{IC}_{50}(\mu \mathrm{M})\end{array}$ & $\begin{array}{l}\text { neuronal NOS } \\
\mathrm{IC}_{50}(\mu \mathrm{M})\end{array}$ & $\begin{array}{c}\text { inducible NOS } \\
\mathrm{IC}_{50}(\mu \mathrm{M})\end{array}$ \\
\hline PF9601N & $82.8 \pm 2.0$ & $164.8 \pm 1.8$ & $187 \pm 1.1$ & $\geq 10^{3}(20 \%)^{*}$ \\
\hline FA72 & $60.2 \pm 1.2$ & $99.4 \pm 1.5$ & $192 \pm 1.0$ & $274 \pm 3.8$ \\
\hline L-Deprenyl & $235.8 \pm 6.0$ & $1120 \pm 5.2$ & $\geq 10^{3}(20 \%)^{*}$ & $\geq 10^{3}(20 \%)^{*}$ \\
\hline
\end{tabular}

*In brackets is reported the percentage of inhibition at compounds concentration $\geq 10^{3} \mu \mathrm{M}$

the compounds were incubated in the presence of $\mathrm{ONOO}^{-}$alone; those changes indicated the formation of new compounds. In a previous study we demonstrated that an arylpropargylamine derivative, structurally related to MAO inhibitors, reacted with peroxynitrite to form a nitramine derivative which was rapidly deaminated to the corresponding 1-phenylpropargyl alcohol (Dragoni et al., 2007). A similar chemical behaviour was observed for guanosine which is modified to 8-hydroxydeoxyguanosine in the presence of peroxynitrite (Inoue \& Kawanishi, 1995). Similar reactions could be hypothesized also for FA72, PF9601N and L-deprenyl; in fact, the nitrogen present in the propargylamine and/or the indole moiety of PF9601N and its metabolite could react with $\mathrm{NOO}^{-}$. The presence of two reactive nitrogen atoms in PF9601N and FA72 could explain their higher potency to react with peroxynitrite as compared to that observed for L-deprenyl. Further studies are needed to identify the pathways of the reactions and their products.

In a similar manner the indole derivatives PF9601N and FA72 were more efficient than L-deprenyl in inhibiting the rat brain NOS. PF9601N and FA72 showed a similar $\mathrm{IC}_{50}$ value, confirming that the indole ring plays an important role in the reactivity of the molecule. Furthermore, the presence of indole was also important for iNOS inhibition. However, the presence of the propargyl moiety decreased the inhibitory effect as observed for L-deprenyl and PF9601N.

Many pieces of indirect evidence such as the pivotal role of NOS in the neurotoxicity of MPTP, the higher resistance to MPTP neurotoxicity in nNOS-deficient mice, the overexpression of nNOS in basal ganglia and in the circulating neutrophils of PD patients as well as the increase of protein tyrosine nitration (for review see Zhou \& Zhu, 2009) support the role of $\mathrm{NO}$ in the pathogenesis of PD lesions. In this context the evidence that PF9601N had neuroprotective effect towards MPTP toxicity at a lower concentration than L-deprenyl had, in both in vivo and in vitro experimental models (Perez et al., 1996; Perez \& Unzeta, 2003), could be ascribed not only to its more effective MAO-B inhibition and its antiapoptotic activity (Sanz, 2008) but also to its interaction with NOS and NOO. Although this effect is observed at a higher concentration than is MAO-B inhibition, it is noticeable that also the CYP-dependent metabolite FA72 is able to interact with the NO system. These observations and the fact that the CYP-dependent metabolism is active also in the brain (Dragoni et al., 2003; Marini et al., 2007) might account for PF9601N being a better neuroprotective compound than L-deprenyl.

\section{Acknowledgements}

This work was realized in the framework of COST working group: D34/0003/05.

\section{REFERENCES}

Avila M, Balsa MD, Fernandez-Alvarez E, Tipton KF, Unzeta M (1993) The effect of side-chain substitution at positions 2 and 3 of the heterocyclic ring of $\mathrm{N}$-acetylenic analogues of tryptamine as monoamine oxidase inhibitors. Biochem Pharmacol 45: 2231-2237.

Beckman JS, Beckman TW, Chen J, Marshall PA, Freeman BA (1990) Apparent hydroxyl radical production by peroxynitrite: implications for endothelial injury from nitric oxide and superoxide. Proc Natl Acad Sci USA 87: 1620-1624.

Beckmann JS, Ye YZ, Anderson PG, Chen J, Accavitti MA, Tarpey MM, White CR (1994) Extensive nitration of protein tyrosines in human atherosclerosis detected by immunohistochemistry. Biol Chem Hoppe Seyler 375: 81-88.

Bolaños JP, Almeida A, Stewart V, Peuchen S, Land JM, Clark JB, Heales SJ (1997) Nitric oxide mediated mitochondrial damage in the brain: mechanisms and implications for neurodegenerative diseases. I Neurochem 68: 2227-2240.

Byun J, Henderson JP, Mueller DM, Heinecke JW (1999) 8-Nitro-2'deoxyguanosine, a specific marker of oxidation by reactive nitrogen species, is generated by the myeloperoxidase-hydrogen peroxidenitrite system of activated human phagocytes. Biochemistry 38: 2590 -2600 .

Chen PF, Tsai AL, BerkaV, Wu KK (1997) Mutation of Glu-361 in human endothelial nitric-oxide synthase selectively abolishes L-arginine binding without perturbing the behaviour of heme and other redox centers. J Biol Chem 272: 6114-6118.

Chiueh CC, Huang SJ, Murphy DL (1994) Suppression of hydroxyl radical formation by MAO inhibitors: a novel possible neuroprotective mechanism in dopaminergic neurotoxicity. I Neural Transm (Suppl) 41: 189-196.

Cutillas B, Ambrosio S, Unzeta M (2002) Neuroprotective effect of the monoamine oxidase inhibitor PF9601N [N-(2-propynyl)-2-(5-benzyloxy-indolyl) methylamine] on rat nigral neurons after 6-OH-DA striatal lesion Neuroscience Letters 329: 165-168.

Dragoni S, Bellik L, Frosini M, Matteucci G, Sgaragli G, Valoti M (2003) Cytochrome P450-dependent metabolism of L-deprenyl in monkey (Cercopithecus aethiops) and C57BL/6 mouse brain microsomal preparations. I Neurochem 86: 1174-1180.

Dragoni S, Materozzi G, Pessina F, Frosini M, Marco JL, Unzeta M, Sgaragli G, Valoti M (2007) CYP-dependent metabolism of PF9601N, a new monoamine oxidase-B inhibitor, by C57BL/6 mouse and human liver microsomes. I Pharm Pharm Sci 10: 473-485.

Dragoni S, Porcari V, Travagli M, Castagnolo D, Valoti M (2006) Antioxidant properties of propargylamine derivatives: assessment of their ability to scavenge peroxynitrite. I Pharm Pharmacol 58: 561565.

Duda JE, Giasson BI, Chen Q, Gur TL, Hurtig HI, Stern MB, Gollomp SM, Ischiropoulos H, Lee VM, Trojanowski JQ (2000) Widespread nitration of pathological inclusions in neurodegenerative synucleinopathies. Am J Pathol 157: 1439-1445.

Hantraye P, Brouillet E, Ferrante R, Palfi S, Dolan R, Matthews RT, Beal MF (1996) Inhibition of neuronal nitric oxide synthase prevents MPTP-induced parkinsonism in baboons. Nat Med 2: $1017-$ 1102.

Hunot S, Boissière F, Faucheux B, Brugg B, Mouatt-Prigent A, Agid Y, Hirsch EC (1996) Nitric oxide synthase and neuronal vulnerability in Parkinson's disease. Neuroscience 72: 355-363. 
Inoue S, Kawanishi S (1995) Oxidative DNA damage induced by simultaneous generation of nitric oxide and superoxide. FEBS Lett 371: $86-88$.

Knoll J (1986) The pharmacology of (-) deprenyl. I Neural Transm (Suppl) 22: 75-89.

Knowels GR, Salter M (1998) Measurement of NOS activity by conversion of radiolabeled arginine to citrulline using ion-exchange separation. In Methods in Molecular Biology, vol 100. Nitric oxide protocols. Michael A, eds, pp 75-84. Titheradge, University of Sussex, Brighton.

Kooy NW, Royall JA, Ischiropoulos H (1997) Oxidation of 2',7'-dichlorofluorescin by peroxynitrite. Free Radic Res 27: 245-254.

Liberatore GT, Jackson-Lewis V, Vukosavic S, Mandir AS, Vila M, McAuliffe WG, Dawson VL, Dawson TM, Przedborski S (1999) Inducile nitric oxide synthase stimulates dopaminergic neurodegeneration in the MPTP model of Parkinson disease. Nat Med 5: 1403-1409.

Lima ES, Di Mascio P, Abdalla DS (2003) Cholesteryl nitrolinoleate, a nitrated lipid present in human blood plasma and lipoproteins. J Lipid Res. 44: 1660-1666.

Marini S, Nannelli A, Sodini D, Dragoni S, Valoti M, Longo V, Gervasi PG (2007) Expression, microsomal and mitochondrial activities of cytochrome P450 enzymes in brain regions from control and phenobarbital-treated rabbits. Life Sci 80: 910-917.

Obeso JA, Olanow CW (1998) Subthalamic nucleus-mediated excitotoxicity in Parkinson's disease: a target for neuroprotection. Ann Neurol 44 (Suppl 1): S175-S188.

O'Donnell VB, Eiserich JP, Chumley PH, Jablonsky MJ, Krishna NR, Kirk M, Barnes S, Darley-Usmar VM, Freeman BA (1999) Nitration of unsaturated fatty acids by nitric oxide-derived reactive nitrogen species peroxynitrite, nitrous acid, nitrogen dioxide, and nitronium ion. Chem Res Toxicol 12: 83-92.

Patel RP, Darley-Usmar VM (1996) Using peroxynitrite as oxidant with low-density lipoprotein. Methods Enaymol 269: 3-?.

Perez V, Marco JL, Fernandez-Alvarez E, Unzeta M (1996) Kinetic studies of $\mathrm{N}$-allenic analogues of tryptamine as monoamine oxidase inhibitors. J Pharm Pharmacol 48: 718-722.

Perez V, Marco JL, Fernandez-Alvarez E, Unzeta M (1999) Relevance of a benzyloxy group in 2-indolyl methylamines in the selective MAO-B inhibition. Br J Pharmacol 127: 869-876.

Perez V, Unzeta M (2003) PF9601N [N-(2-propynyl)-2-(5-benzyloxyindolyl) methylamine], a new MAO-B inhibitor, attenuates MPTP- induced depletion of striatal dopamine levels in C57/BL mice Neurochem Intern 42: 221-229.

Prat G, Pérez V, Rubi A, Casas M, Unzeta M (2000) The novel type-B MAO inhibitor PF9601N enhances the duration of L-DOPA-induced contralateral turning in 6-hydroxydopamine lesioned rats. $J$ Neural Transm 107: 409-417.

Przedborski S, Jackson-Lewis V, Yokoyama R, Shibata T, Dawson VL, Dawson TM (1996) Role of neuronal nitric oxide in 1-methyl4-phenyl-1,2,3,6-tetrahydropyridine (MPTP)-induced dopaminergic neurotoxicity. Proc Natl Acad Sci USA 93: 4565-4571.

Rodriguez MC, Obeso JA, Olanow CW (1998) Subthalamic nucleusmediated excitotoxicity in Parkinson's disease: a target for neuroprotection. Ann Neurol 44: S175-S188.

Sanz E, Quintana A, Battaglia V, Toninello A, Hidalgo J, Ambrosio S, Valoti M, Marco JL, Tipton KF, Unzeta M (2008) Anti-apoptotic effect of Mao-B inhibitor PF9601N [N-(2-propynyl)-2-(5-benzyloxyindolyl) methylamine] is mediated by p53 pathway inhibition in $\mathrm{MPP}^{+}$-treated SH-SY5Y human dopaminergic cells. J Neurochem 105: 2404-2417.

Sanz E, Quintana A, Hidalgo J, Marco JL, Unzeta M (2009) PF9601N [N-(2-propynyl)-2-(5-benzyloxy-indolyl) methylamine] confers MAO-B independent neuroprotection in ER stress-induced cell death. Mol Cell Neurosci 41: 19-31.

Sanz E, Romera M, Bellik L, Marco JI, Unzeta M (2004) Indolalkylamines derivatives as antioxidant and neuroprotective agents in an experimental model of Parkinson's disease. Med Sci Monit 10: BR477-BR484.

Schapira AH, Cooper JM, Dexter D, Clark JB, Jenner P, Marsden CD (1990) Mitochondrial complex I deficiency in Parkinson's disease. J Neurochem 54: 823-827.

Schulz JB, Matthews RT, Muqit MM, Browne SE, Beal MF (1995) Inhibition of neuronal nitric oxide synthase by 7 -nitroindazole protects against MPTP-induced neurotoxicity in mice. J Neurochem 64: 936-939.

Zhou L, Zhu DY (2009) Neuronal nitric oxide synthase: structure, subcellular localization, regulation, and clinical implications. Nitric Oxide 20: 223-230. 